\title{
Characteristics of a Sinusoidally-Distributed Cylindrical-Rotor Self-Excited Single-Phase Synchronous Generator
}

\author{
Helmy Awad ${ }^{1}$, Elwy E. Elkholy ${ }^{2}$ \\ ${ }^{I}$ Faculty of Technology and Industrial Education, Helwan University, Cairo, Egypt \\ ${ }^{2}$ Electric Eng. Dept., Faculty of Engineering, Menoufia University, Egypt.
}

\begin{abstract}
The small-scale power systems favor the installation of self-excited synchronous generators due to their simple construction. Many configurations were reported in the literature but there have been always two issues: voltage regulation (VR) and total harmonic distortion (THD) of the output voltage. This paper presents an experimental investigation to improve the performance of single-phase, self-excited, synchronous generator (SPSESG) in terms of the VR and THD. The applied modification is the implementation of sinusoidallydistributed stator windings which implies a different number of turns in each slot. A typical lab single-phase synchronous machine was rewound with the proper number of turns in each slot and then tested against resistive, resistive-inductive, resistive-capacitive, and dynamic loads (induction motor).

The experimental results proved that the modified generator performance has significantly improved in terms of the VR and THD. The worst VR was recorded in the case of dynamic load and it was $6.5 \%$. While the highest THD was $4.5 \%$, at no load. These figures are much better than other configurations reported in the literature.
\end{abstract}

Keywords: Self-excited; Sinusoidally-distributed windings; Synchronous generator; Voltage regulation.

\section{INTRODUCTION}

For standalone (isolated) energy systems, selfexcited generators offer a viable solution $[1,2,3]$ because of their simple construction and high reliability. Three-phase self-excited induction generators are implemented in standalone applications, particularly in wind power systems $[4,5,6]$. Most commonly, three-phase self-excited synchronous generators are exploited in many applications $[7,8,9]$. However, in the case of smallscale power systems such as micro-hydro, a singlephase self-excised synchronous generator (SPSESG) is more suited $[10,11,12,13]$.

Few configurations of SPSESG have been reported and well-explained in literature such as Series Connected Synchronous Generator [14,15,16], Cylindrical Rotor Synchronous Generator,
Reluctance Synchronous Generator [9, 17], Converted three- to single-phase Synchronous Generator $[18,19]$. In the latter configuration, a typical six-winding machine is reconfigured to serve as a SPSESG $[19,20,21]$ where the rotor windings are shorted by diodes and one stator phase is connected via a capacitor. The other two phases of the stator are connected in series to form the load terminals. A schematic diagram of this generator is shown in Fig. 1. The main issues reported for such SPSESG were the total harmonic distortion (THD) and voltage regulation (VR) [19]. For various load conditions, the highest THD was $15 \%$ in the case of induction-motor load. While the highest VR was $18 \%$ in the case of the resistive-capacitive load.

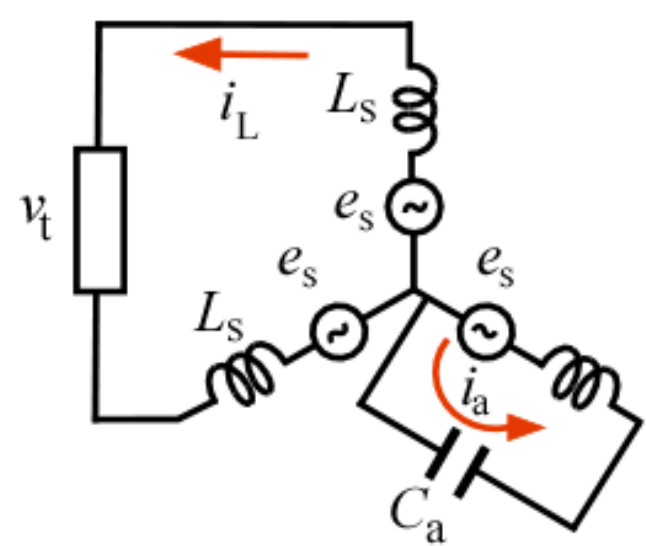

Stator Windings

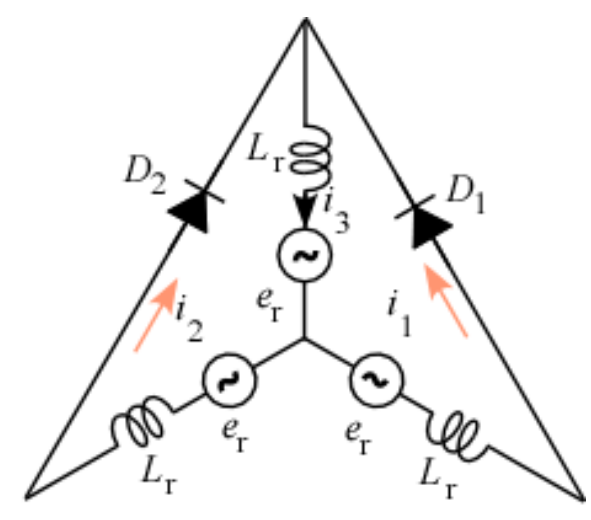

Rotor Windings

Figure1- Schematic diagram of a converted three- to single-phase synchronous generator 
This paper presents the experimental results of a modified SPSESG where the above-mentioned issues are minimized. Section II of the paper presents the proposed modifications while Section III displays the experimental results at no loads and various loading conditions. Section IV presents a comparison between the modified generator and the converted three- to single-phase generator.

\section{PROPOSED MODIFICATION}

In this work, the typical field winding of a synchronous generator was used but shorted via a diode so that the field current is unidirectional and the rotor magnetization axis in space is fixed.

The stator windings involve both main and auxiliary coils where the auxiliary windings are connected to a variable capacitor. Adjusting the value of the capacitance represents a key to the operation of the generator and can be used for voltage regulation. Fig. 2 shows a schematic diagram of the modified SPSESG. The basic idea of the self-excitation can be summarized as follows. The rotor field winding is rotated by a prime mover with a constant speed, which induces a small amount of voltage on the stator main windings due to the residual magnetism. Also, the field current is induced in the rotor windings which is then rectified by the diode. Increasing the value of the capacitance in the auxiliary windings increases the current induced in field windings and so on until a critical value of the capacitor is reached after which the induced voltage builds up and then the generator is successfully started.

The main proposed modification is to exploit sinusoidally-distributed windings in the main and auxiliary coils. The magnetic axes of these windings must have a $90^{\circ}$ displacement space, despite that they are composed of coils distributed in space around the air gap periphery.
If the produced flux is sinusoidally distributed in space, then the induced voltage would be sinusoidal in time [22]. To reduce the THD of the induced voltage waveform, sinusoidallydistributed windings arrangements are proposed for both main and auxiliary windings.

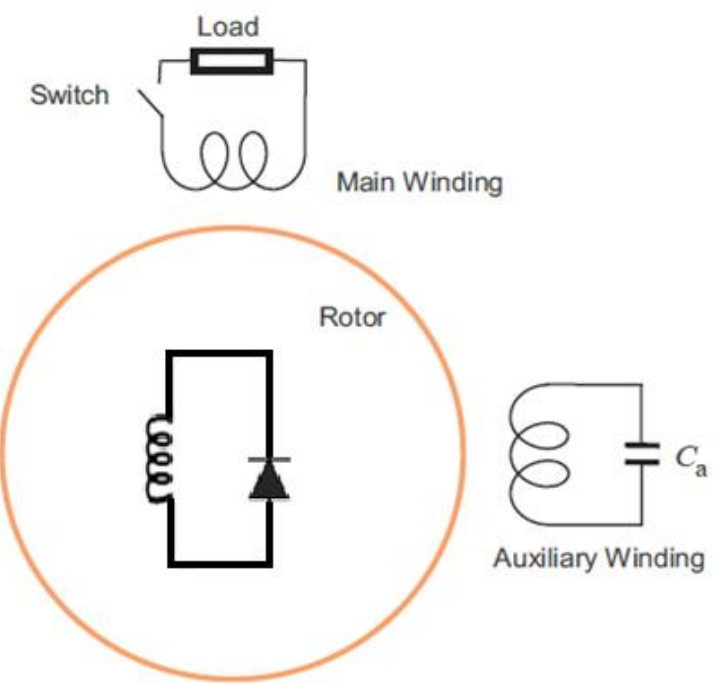

Figure 2- Construction of AC machine under investigation

The main and auxiliary windings are wound using the distributed concentric single-phase winding method as it offers high-quality flux distribution and higher efficiency [23]. In such a winding, the outer coils of each pole have a longer span and a higher pitch factor while the inner coils have the advantage of a shorter end connection. For a 24slot 2-pole stator, the layout of the winding is illustrated in Fig. 3, where M1 and M2 are the terminals of the main windings while A1 and A2 are the terminals of the auxiliary windings.

To achieve a sinusoidal distribution of the field flux, the number of conductors in each slot is varied according to the sine half the angle of the coil span like that given in Table 1.

Table 1- Sinusoidal distribution of stator windings

\begin{tabular}{|c|c|c|c|c|c|}
\hline \multicolumn{4}{|c|}{ Main Windings } & \multicolumn{2}{|c|}{$\begin{array}{c}\text { Auxiliary } \\
\text { Winding }\end{array}$} \\
\hline $\begin{array}{l}\text { Coil } \\
\text { Span }\end{array}$ & $\begin{array}{l}\text { Angle } \\
{[\text { Deg] }}\end{array}$ & $\begin{array}{c}\sin \\
(\text { Angle/2) }\end{array}$ & $\begin{array}{c}\% \text { of Turns }= \\
100 * \sin \\
(\text { Angle/2)/sum }\end{array}$ & $\begin{array}{l}\text { Coil } \\
\text { Span }\end{array}$ & $\begin{array}{l}\% \text { of } \\
\text { Turns }\end{array}$ \\
\hline $1-13$ & 90 & 0.70711 & 27.34 & $7-19$ & 27.34 \\
\hline $2-12$ & 75 & 0.60876 & 23.54 & $8-18$ & 23.54 \\
\hline $3-11$ & 60 & 0.5 & 19.33 & $9-17$ & 19.33 \\
\hline $4-10$ & 45 & 0.38268 & 14.79 & $10-16$ & 14.79 \\
\hline $5-9$ & 30 & 0.25882 & 10.00 & $11-15$ & 10.00 \\
\hline $6-8$ & 15 & 0.13053 & 5.00 & $12-14$ & 5.00 \\
\hline
\end{tabular}




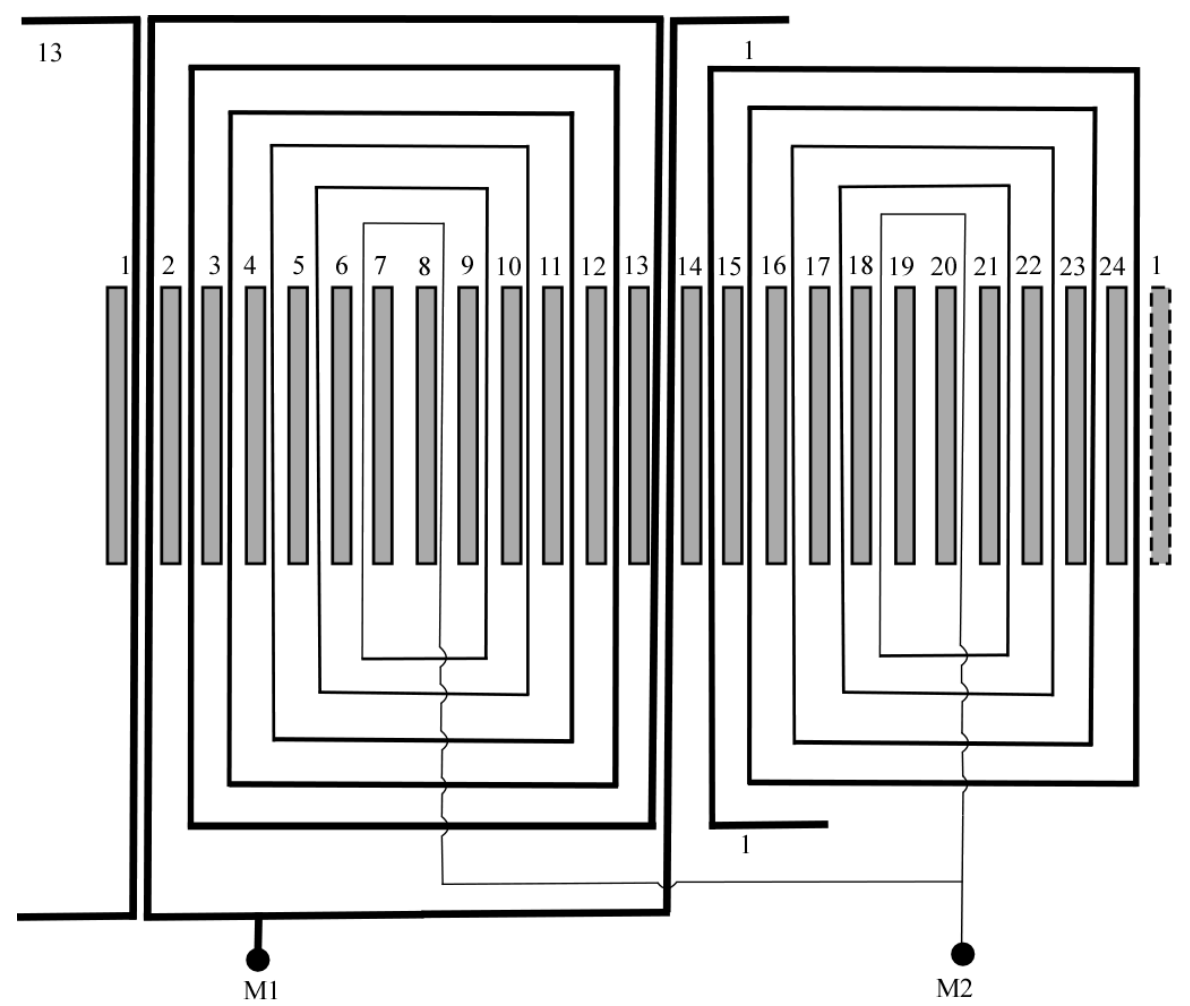

(a)
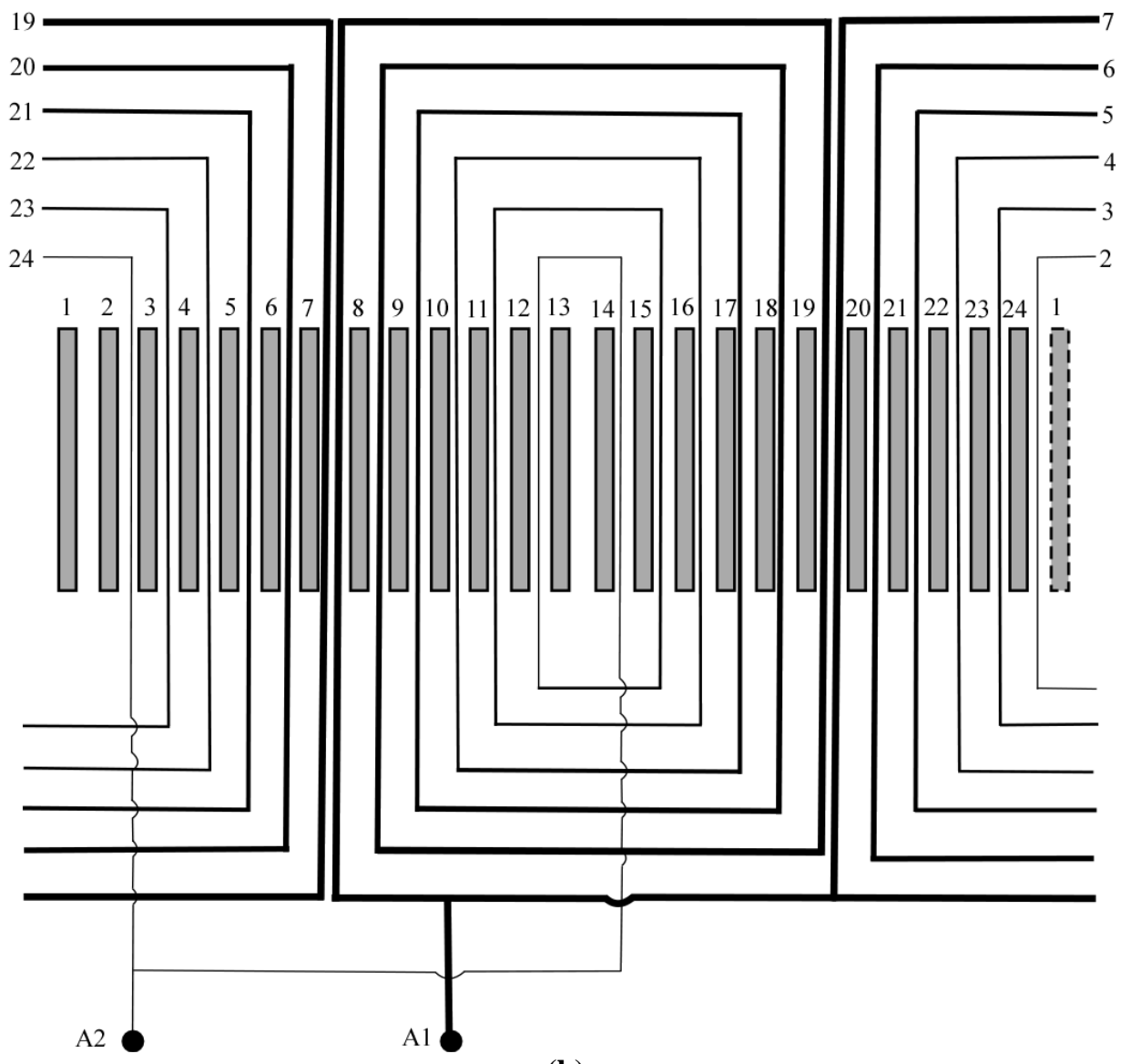

(b)

Figure 3- Windings layout of presented design: of SPSESG: (a) main winding and (b) auxiliary winding 


\section{EXPERIMENTAL RESULTS}

\section{A. No-Load Characteristics}

The rewound SG was coupled to a prime mover which is a $220-\mathrm{V}$ dc shunt motor as shown in Fig. 4 , where a variable capacitor is used to adjust the field current of the generator. Also, the output terminals of the SPSESG was connected to a voltage transformer $(2: 1)$ to be able to use the only available oscilloscope props (1:10 and 1:20). Before inserting the capacitor in the circuit, the output voltage waveform was measured and recorded as shown in Fig. 5. Of course, this voltage is generated due to the residual magnetism and it is essential for successful operation. If for any reason, the residual magnetism does not exist, the field winding should be opened, and a proper dc source is connected to inject the rated current for a few minutes. After that, the generator can be tested.

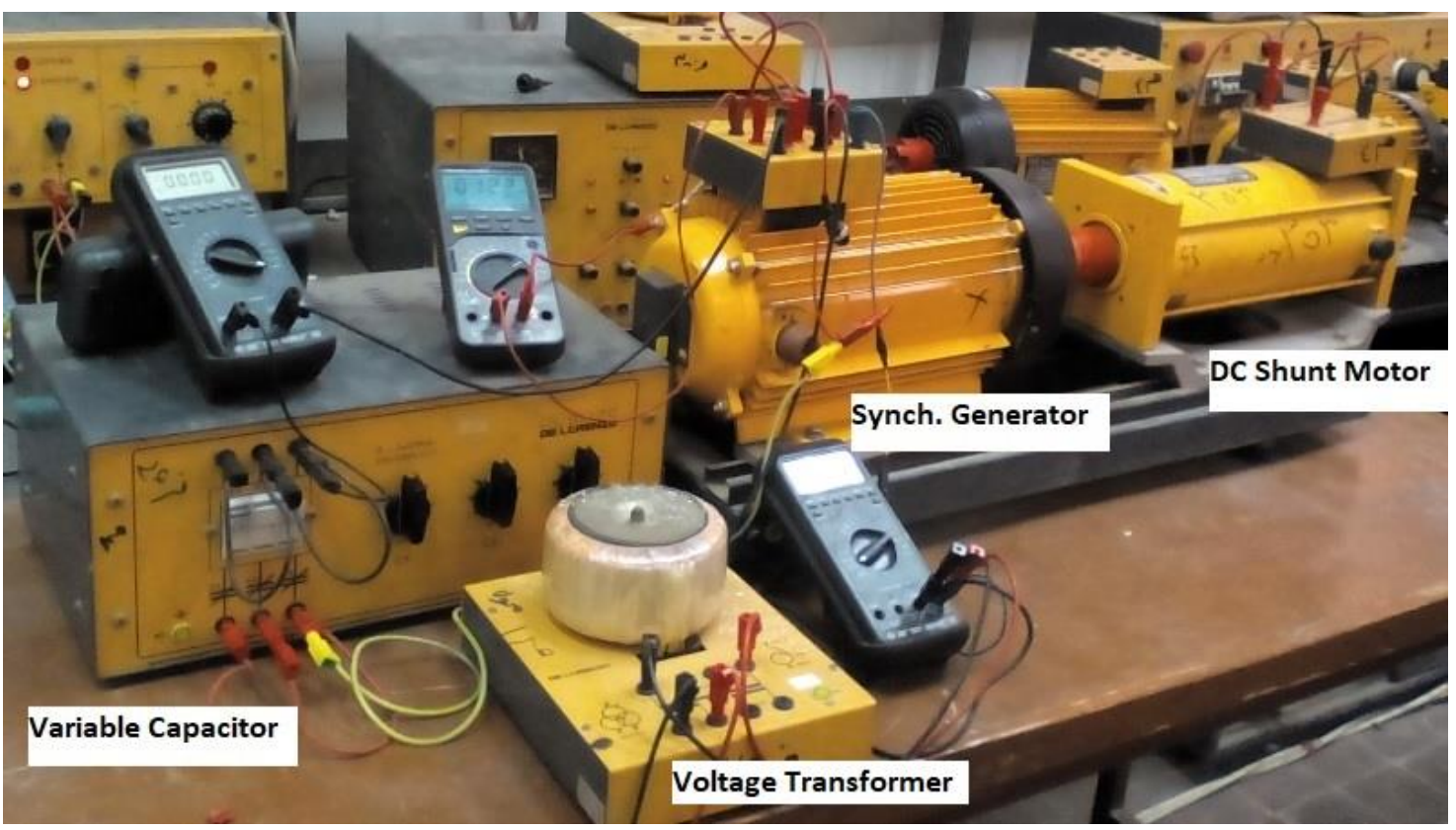

Figure 4- Photo of the experimental setup of the SPSESG.

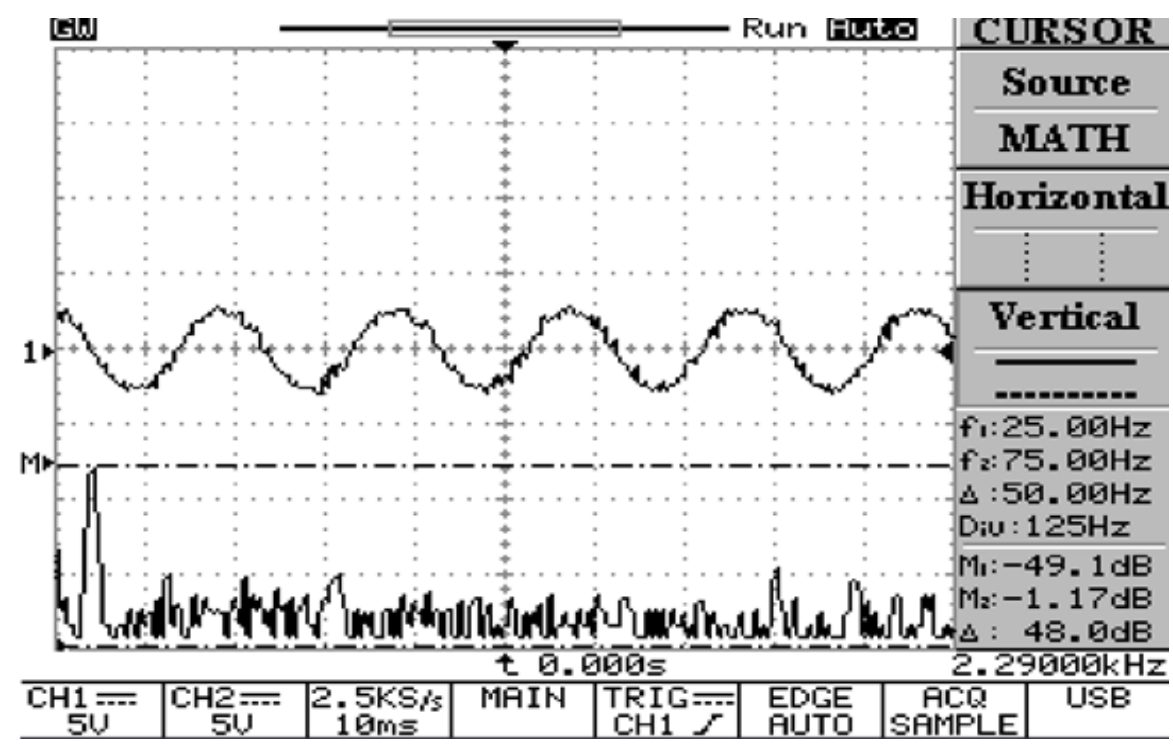

Figure 5- Waveform and harmonic content of output voltage due to residual magnetism.

After that, the capacitor size was increased step by step until the output voltage buildup is successful. In each step, the Field current $\left(I_{\mathrm{F}}\right)$ and the output voltage harmonics are recorded. For instance,
Fig. 5 shows the output voltage waveform when the capacitor size was increased to $\mathrm{C}=20.27 \mu \mathrm{F}$. As the capacitor size increases, the RMS value of output voltage increases. 


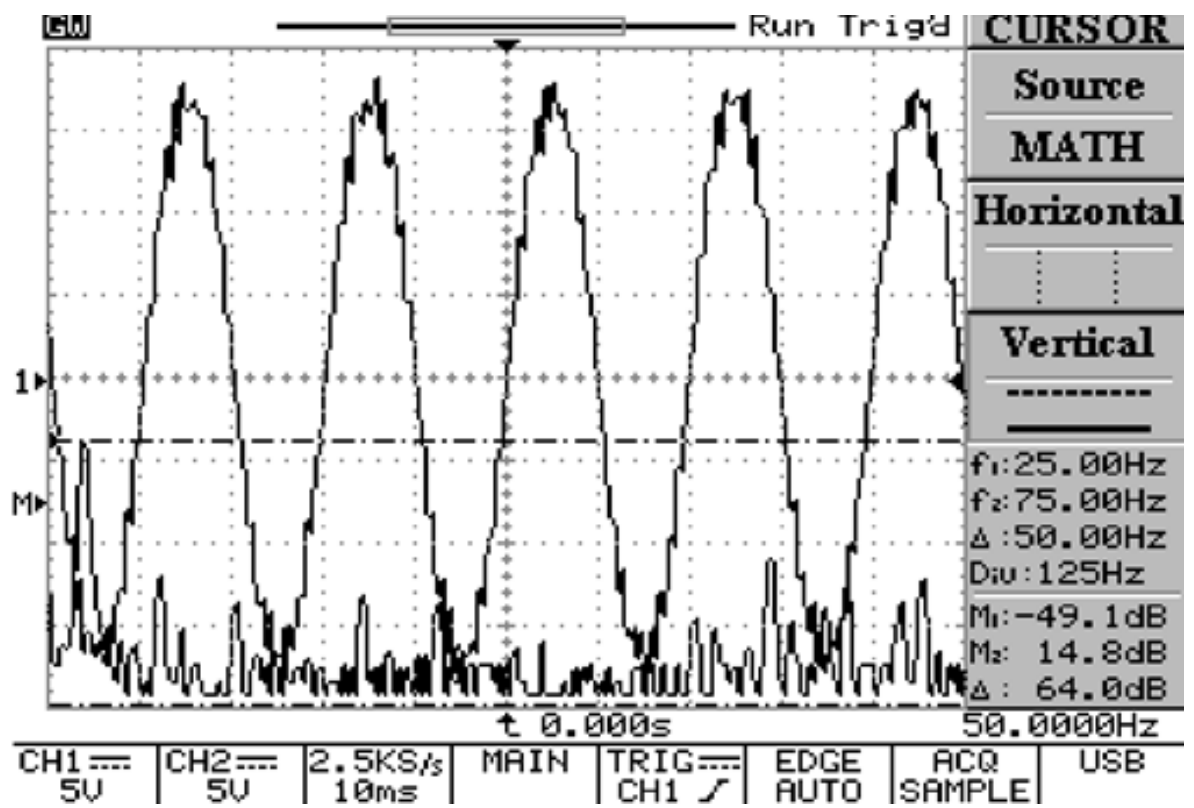

Figure 6. Waveform and harmonic content of output voltage at $\mathrm{C}=20.27 \mu \mathrm{F}$

The influence of the capacitor size on the amount of the field current is displayed in Fig. 7. At the beginning up to $\mathrm{C}=8.052 \mu \mathrm{F}$, the field current increases very slowly until it jumps at $C=10.2 \mu \mathrm{F}$

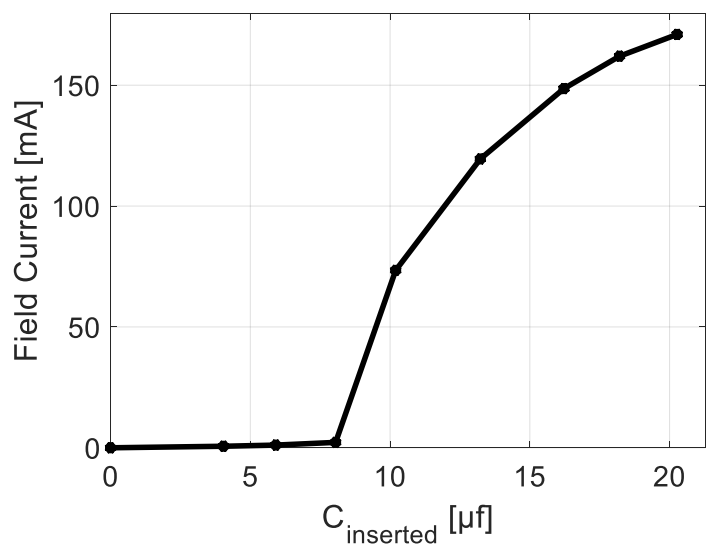

Figure 7- Field current versus the capacitor size at no load

The no-load characteristics of the SPSESG are displayed in Fig. 8. When there is no field current, the output voltage is $6.8 \mathrm{~V}$ due to the residual magnetism. As the field current increases, the output voltage increases linearly up to $377 \mathrm{~V}$ after which it starts to saturate. The saturation of the output voltage is a response to the slowly saturating field current after $C=13.3 \mu \mathrm{F}$. The output voltage saturates as the field current increases further in the same manner as an externally excited synchronous generator. With a deeper look at Fig.8, the change of the magnetizing reactance and or inductance can be approximately estimated. The non-saturating inductance is roughly $212 \mathrm{mH}$ while the saturating inductance is $72 \mathrm{mH}$ on average. and the field current reaches $73.4 \mathrm{~mA}$. The capacitor size is increased to 20.27 at which the field current becomes $171 \mathrm{~mA}$.

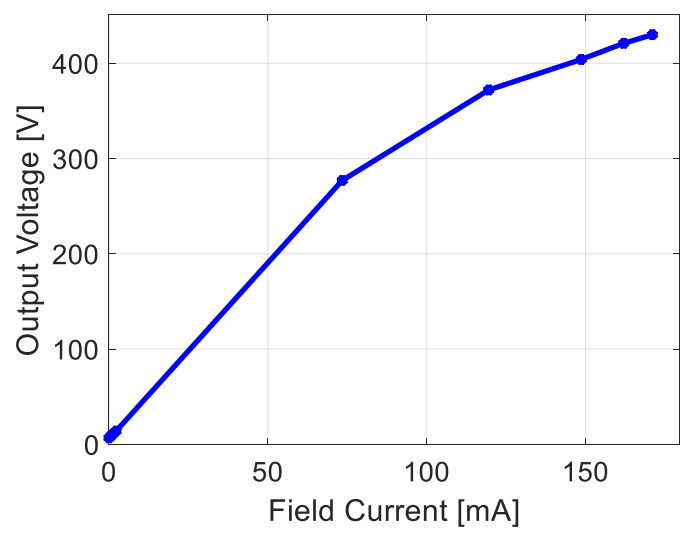

Figure 8- No-load characteristics of the SPSESG

To visualize the amount of harmonic distortion, the fundamental, $3^{\text {rd }}$, and $5^{\text {th }}$ components of the output voltage are displayed in Fig. 9. The $3^{\text {rd }}$ and the $5^{\text {th }}$ are close to each other, although the $3^{\text {rd }}$ is a little bit larger. The general trend is that they increase as the capacitor size increases. Considering only the $3^{\text {rd }}$ and the $5^{\text {th }}$ harmonics, the THD is calculated and plotted as given in Fig. 10 . It is noted that the maximum THD is $0.044 \mathrm{pu}$ and it is minimum at $C=10.2 \mu \mathrm{F}$. The minimum THD was obtained because the increase of the fundamental component is larger than the increase of the individual harmonics. After that, the THD increases slightly due to the saturation effect. 


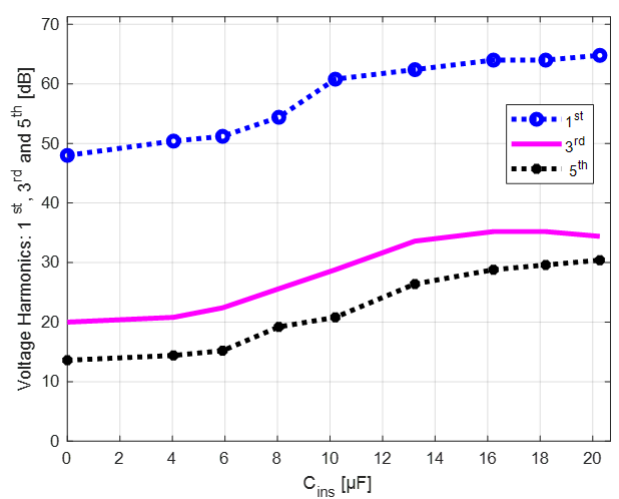

Figure $9-1^{\text {st }}, 3^{\text {rd }}$ and $5^{\text {th }}$ harmonics of the out voltage versus the capacitor size at no load

\section{B. Loading Characteristics}

\section{B.1. Static Loads}

The generator was tested with resistive, resistiveinductive, and resistive-capacitive loads. The tests were limited to those loads available in the lab. In each load step, the output voltage $\left(V_{\mathrm{t}}\right)$, the armature current $\left(I_{\mathrm{a}}\right)$, and the harmonic components: $1^{\text {st }}, 3^{\text {rd }}$, and $5^{\text {th }}$ of the output voltage are recorded. Fig. 11 depicts the load characteristics of the three load types. The voltage regulation (VR) is the least $(5.67 \%)$ in the case of the resistive-inductive load. However, it will be even lower if the load is increased. But on the other hand, the generator is working steadily under the three load types.

The $3^{\text {rd }}$ and $5^{\text {th }}$ harmonics of the load voltage are displayed versus the load current for the three load types in Fig 12 . The $3^{\text {rd }}$ harmonic generally decreases as the load increases and its maximum is $3.3 \%$. Regarding the $5^{\text {th }}$ harmonic, in the case of resistive-inductive load, it increases as the load increases but on the other two cases, it decreases.

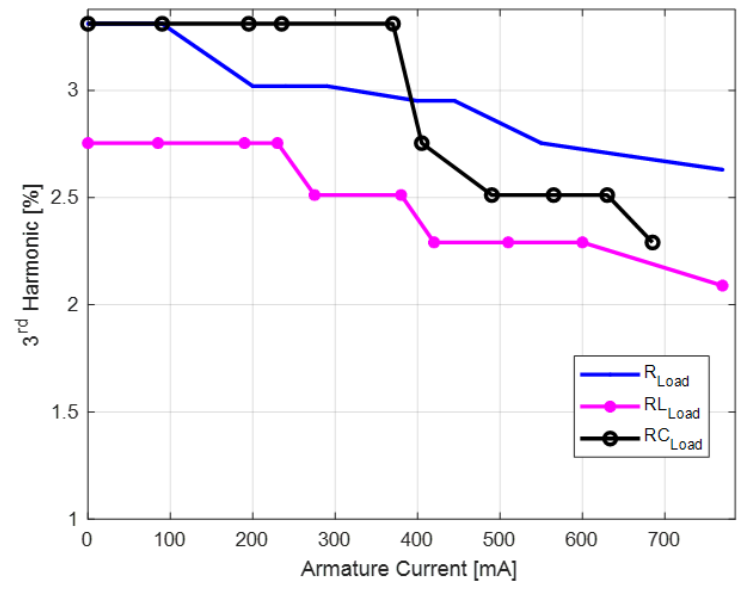

(a)

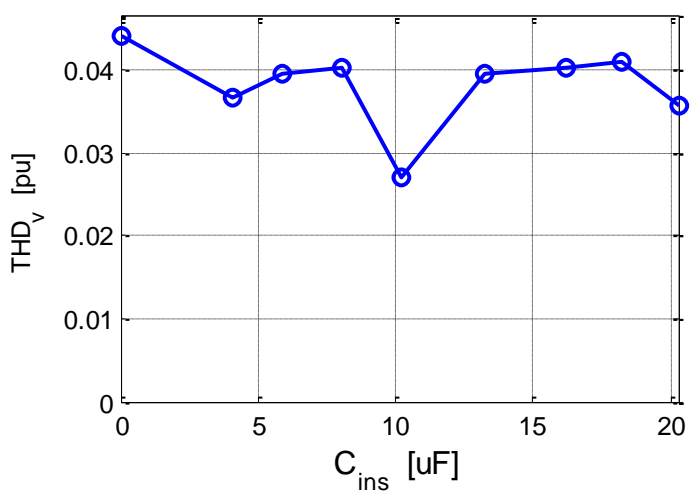

Figure 10- Total Harmonic Distortion of the output voltage in case of no load

The maximum of the $5^{\text {th }}$ harmonic was $2.5 \%$ in the case of the resistive-inductive load. Based on the $3^{\text {rd }}$ and $5^{\text {th }}$ harmonics, the THD was calculated and is displayed in Fig. 13. The general trend noticed from Fig.13 is that the THD decreases as the load increases.

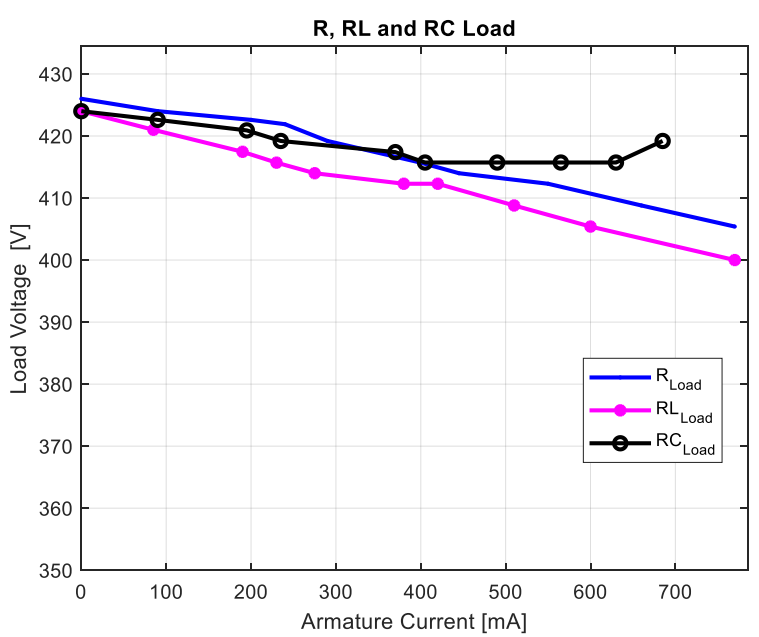

Figure 11- Load characteristics of SPSESG in case of static loads

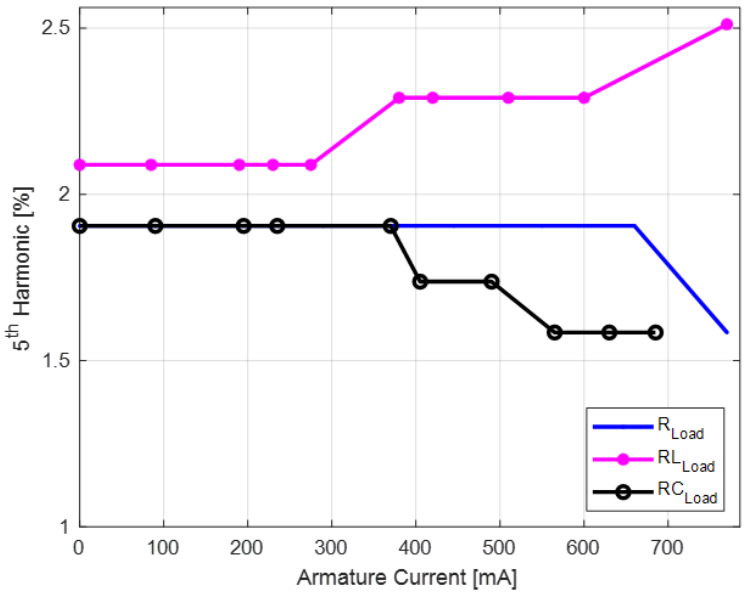

(b)

Figure 12- Percentage of Harmonics of load voltage of SPSESG in case of static loads: (a) $3^{\text {rd }}$ and (b) $5^{\text {th }}$ 


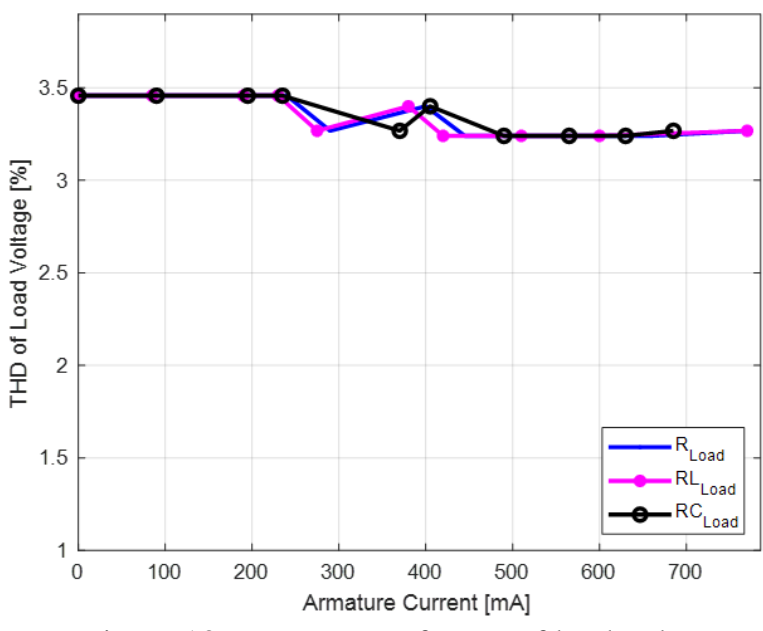

Figure 13- Percentage of THD of load voltage of SPSESG in case of static loads

\section{B.2. Dynamic Load: Single-Phase Induction Motor}

A single-phase induction motor is connected across one of the stator phases and a mechanical brake is applied to the motor to vary its load. Fig. 14 presents the load characteristics of the SPSESG in this case. The minimum drawn current was 1.6 A which yields an output voltage of $157 \mathrm{~V}$. When the armature current increases to $2.3 \mathrm{~A}$, the generator output voltage decreases to $148 \mathrm{~V}$ and the corresponding VR is $6.5 \%$.

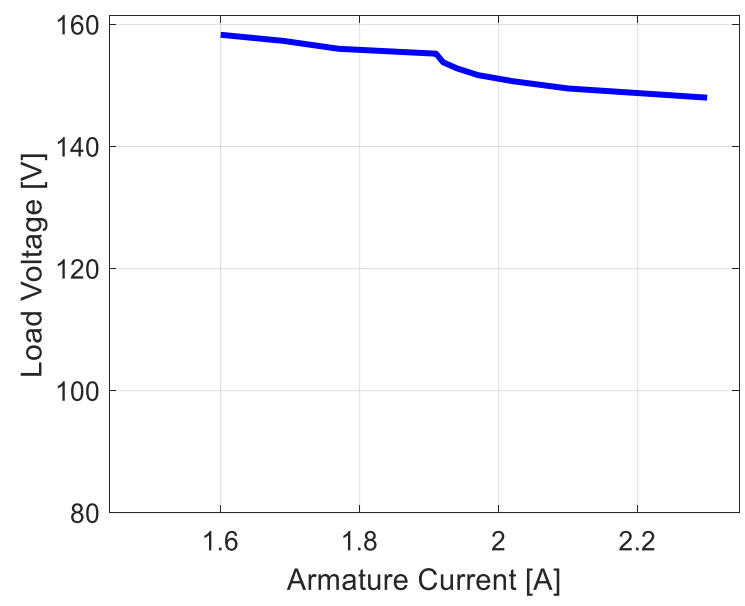

Figure 14- Load characteristics of SPSESG in case of induction-motor load

\section{DISCUSSIONS}

Here, the performance of the modified SPSESG is compared to the configuration presented in [19]. The comparison is concluded in Table 3, where it is clear that the VR has improved. For instance, taking the case of induction motor in both configurations, the VR has decreased from 14 to $6.5 \%$. This is a considerable achievement. Regarding the THD of the output voltage, it
Fig. 15 shows the $3^{\text {rd }}, 5^{\text {th }}$ harmonics, and the THD of the output voltage in the case of inductionmotor load. It is noted that the $5^{\text {th }}$ harmonic is constant at $5.25 \%$ while the $3^{\text {rd }}$ harmonic drops from 8.3 to $7.6 \%$. The THD decreased from 8.45 at no load to 7.84 at full load. The presence of harmonics is evident also in the voltage waveform as shown in Fig. 16.

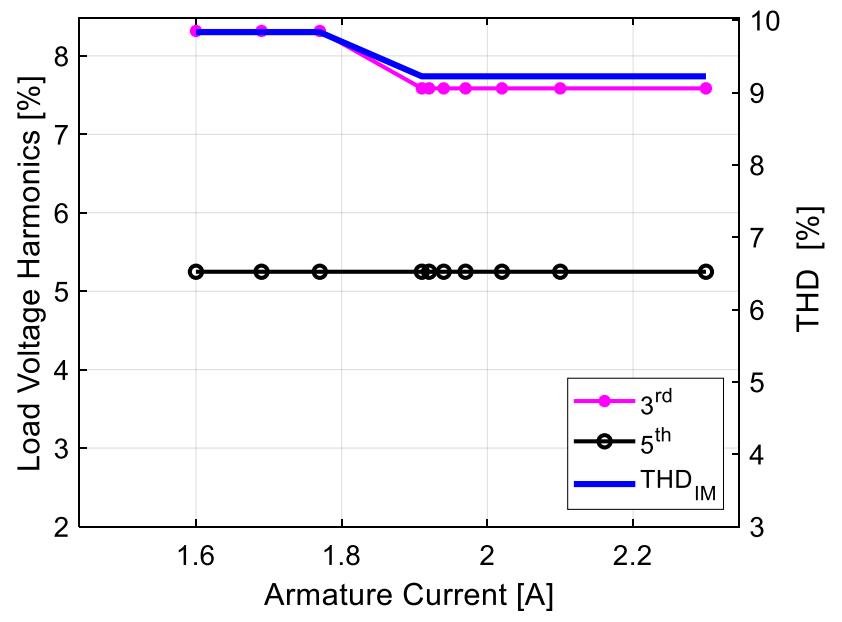

Fig. 15. \% Harmonics of load voltage of SPSESG in case of induction-motor 1

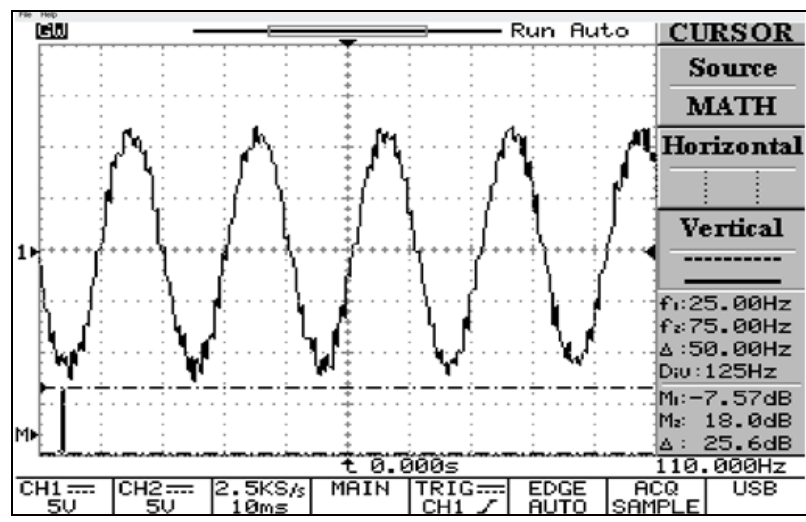

Fig. 16. Waveform of the output voltage of SPSESG in case of induction-motor load

decreased from $13.5 \%$ to $4.45 \%$, which is also a considerable achievement. However, it needs more work to completely understand and analyze the performance of this type of generator. Detailed models are required considering the high nonlinearity caused by the presence of the diode in the rotor field circuits. Automatic voltage regulators for this generator may be a good area of research in this context. 
Table 3-Comparison between the converted three-phase to single-phase configuration and the proposed modified SPSESG

\begin{tabular}{lccccc}
\hline \multirow{2}{*}{ Type load } & \multicolumn{2}{c}{ Converted 3-ph to1-ph } & & \multicolumn{2}{c}{ Modified SPSESG } \\
\cline { 2 - 3 } \cline { 6 - 7 } & THD pu & VR $\%$ & & THD pu & VR \% \\
\hline No-load & 0.135 & -- & & 0.0441 & -- \\
Resistive & 0.0459 & 16 & & 0.0382 & 4.8 \\
Resistive-capacitive & 0.0471 & 18 & & 0.0382 & 1.96 \\
Resistive-inductive & 0.0516 & 12 & & 0.0346 & 5.67 \\
Dynamic loads & 0.15 & 14 & & 0.10 & 8.1 \\
\hline
\end{tabular}

\section{CONCLUSIONS}

The design of the self-excited synchronous generator has been modified and tested against static and dynamic loads. Static loads include resistive, resistive-capacitive, and resistiveinductive. Dynamic loads are represented by a single-phase induction motor with mechanical braking. It was found that the generator performance was satisfactorily robust in terms of the output voltage regulation. The maximum voltage regulation was $6.5 \%$, which was less than other configurations reported in the literature. The total harmonic distortion was also reduced to 6.5 $\%$ maximal compared to $13.5 \%$ other configurations. Detailed modeling of such generators is highly recommended to fully understand and control its performance.

\section{REFERENCES}

[1] W. E. Vanço, F. B. Silva, C. M. R. De Oliveira, J. R. B. A. Monteiro, and J. M. M. De Oliveira, "A Proposal of Expansion and Implementation in Isolated Generation Systems Using Self-Excited Induction Generator With Synchronous Generator," in IEEE Access, vol. 7, pp. 117188-117195, 2019.

[2] Y. Wang and N. Bianchi, "Investigation of Self-Excited Synchronous Reluctance Generators," in IEEE Transactions on Industry Applications, vol. 54, no. 2, pp. 13601369, March-April 2018.

[3] W. E. Vanço, F. B. Silva, F. A. S. Gonçalves, E. O. Silva, C. A. Bissochi, and L. M. Neto, "Experimental analysis of self-excited induction generators operating in parallel with synchronous generators applied to isolated load generation," in IEEE Latin America Transactions, vol. 14, no. 4, pp. 1730-1736, April 2016.

[4] N. Bouchiba, S. Salem, and M. B. A. Kammoun, "Three-phase self-excited induction generator analysis in stand-alone mode," IREC2015 The $6^{\text {th }}$ International
Re- newable Energy Congress, Sousse, 2015, pp. 1-6.

[5] R. C. Bansal, "Three-phase self-excited induction generators: an overview," in IEEE Transactions on Energy Conversion, vol. 20, no. 2, pp. 292-299, June 2005.

[6] K. A. Chinmaya and G. K. Singh, "Performance evaluation of multiphase induction generator in stand-alone and gridconnected wind energy conversion system," in IET Renewable Power Generation, vol. 12, no. 7, pp. 823-831, 2152018.

[7] Y. Wang and N. Bianchi, "Investigation of Self-Excited Synchronous Reluctance Generators," in IEEE Transactions on Industry Applications, vol. 54, no. 2, pp. 1360-1369, March-April 2018.

[8] C. Chakraborty and Y. T. Rao, "Performance of Brushless Induction Excited Synchronous Generator," in the IEEE Journal of Emerging and Selected Topics in Power Electronics, vol. 7, no. 4, pp. 2571-2582, Dec. 2019.

[9] S. S. Maroufian and P. Pillay, "Self-Excitation Criteria of the Synchronous Reluctance Generator in Stand-Alone Mode of Operation," in IEEE Transactions on Industry Applications, vol. 54, no. 2, pp. 1245-1253, March-April 2018.

[10] S. Nonaka and K. Kesamaru, "Analysis of new brushless self-excited single-phase synchronous generator by finite element method," Conference Record of the 1992 IEEE Industry Applications Society Annual Meeting, Houston, TX, USA, 1992, pp. 198203 vol.1.

[11] F. Shibata and T. Kohrin, "A Brushless, SelfExcited Single-Phase Synchronous Generator Operating with Load and Exciting Currents Flowing in Armature," in IEEE Transactions on Energy Conversion, vol. EC-2, no. 2, pp. 254-261, June 1987. 
[12] W. S. Abu-Elhaija and A. Muetze, "SelfExcitation and Stability at Speed Transients of Self-Excited Single-Phase Reluctance Generators," in IEEE Transactions on Sustainable Energy, vol. 4, no. 1, pp. 136-144, Jan. 2013.

[13] F. Shibata and N. Naoe, "Characteristics of brushless and exciter-less, self-excited synchronous generators," Conference Record of the 1990 IEEE Industry Applications Society Annual Meeting, Seattle, WA, USA, 1990, pp. 293-300 vol.1.

[14] M. F. Moussa, Y. G. Dessouky and B. W. Williams, "Control strategy of a 6 MVA Series Connected Synchronous Generator for wind power," IET Conference on Renewable Power Generation (RPG 2011), Edinburgh, 2011, pp. 1-6.

[15] Tze-Fun Chan, Weimin Wang, and L. L. Lai, "Series-connected self-excited synchronous generator for distributed generation," IEEE PES General Meeting, Providence, RI, 2010, pp. 1-6.

[16] A. L. Mohamadein, H. A. Yousef, and Y. G. Dessouky, "Series-connected self-excited synchronous generator: steady-state and transient behaviors," in IEEE Transactions on Energy Conversion, vol. 14, no. 4, pp. 11081114, Dec. 1999.

[17] F. Rebahi, A. Bentounsi, H. Khelifa, O. Boulkhrachef, and D. Meherhera, "Comparative study of a self-excited induction and synchronous reluctance generators capabilities," 2019 International Conference on Advanced Electrical Engineering (ICAEE), Algiers, Algeria, 2019, pp. 1-5.
[18] M. Abdelrazek, H. Awad, and E. E. El-Kholy, "An experimental investigation of a selfexcited synchronous generator: Loading characteristics and output voltage harmonics," 2017 Nineteenth International Middle East Power Systems Conference (MEPCON), Cairo, 2017, pp. 823-829.

[19] Hilmy Awad, Mohamed Wadi, Essam Hamdi, "A self-excited synchronous generator for small hydro applications", in Proceedings of the International. Conference on Energy, Environment, Ecosystems, and Sustainable Development, 2005, pp. 1-5

[20] S. Nonaka and T. Kawaguchi, "A new variable-speed AC generator system using a brushless self-excited-type synchronous machine," IEEE Transactions on Industry Applications, Vol. 28, No. 2, pp.490-496, March-April 1992.

[21] S. Nonaka and T. Kawaguchi, "Excitation scheme of brushless self-excited type threephase synchronous machine," in Proc. of IEEE Industry Applications Society Annual Meeting, Vol. 1, pp. 443-448, 28 Sept.-4 Oct. 1991.

[22] BUKSNAITIS, J., 2018. Sinusoidal ThreePhase Windings Of Electric Machines, Springer International Publishing Switzerland, ISBN 978-3-319-42929-8.

[23] M. A. Kabir, M. Z. M. Jaffar, Z. Wan and I. Husain, "Design and experimental evaluation of a multilayer $\mathrm{AC}$ winding configuration for sinusoidal MMF with shorter end-turn length," 2017 IEEE Energy Conversion Congress and Exposition (ECCE), Cincinnati, OH, 2017, pp. 5834-5839. 